\title{
Air-plasma spraying colloidal solutions of nanosized ceramic powders
}

\author{
ZUN CHEN, RODNEY W. TRICE \\ School of Materials Engineering, Purdue University \\ E-mail: rtrice@ecn.purdue.edu
}

M. BESSER, XIAOYUN YANG, D. SORDELET

Metal and Ceramic Sciences Program, Ames Laboratory (USDOE), lowa State University, Ames, lowa

Coatings prepared from nanosized powders were obtained by spraying ethanol-based colloidal solutions into a plasma plume. The powders investigated included $40 \mathrm{~nm} \gamma-\mathrm{Al}_{2} \mathrm{O}_{3}$, $75 \mathrm{~nm} 8 \mathrm{wt} \% \mathrm{Y}_{2} \mathrm{O}_{3}-\mathrm{ZrO}_{2}$, and $750 \mathrm{~nm} 25 \mathrm{wt} \% \mathrm{CeO}_{2}-\mathrm{ZrO}_{2}$. Spray distances from approximately 50 to $63 \mathrm{~mm}$ were required to achieve significant coating deposition. As observed in the TEM, the typical lamella morphology of air plasma sprayed oxide coatings was not observed in coatings fabricated from $40 \mathrm{~nm} \gamma-\mathrm{Al}_{2} \mathrm{O}_{3}$, which was comprised of spherical powders that had partially sintered. However, lamellae were observed in the coatings prepared with both nanosized zirconia powders. The characteristic size of the lamella and the grains that comprised the zirconia coatings were nominally a few nanometers. (c) 2004 Kluwer Academic Publishers

\section{Introduction}

The state-of-the-art plasma spray process for ceramics employs large ceramic powders (often greater than $50 \mu \mathrm{m}$ ) that are fed into a plasma plume [1,2]. The powders are fed through a long supply hose via gas flow into an injector that is located very near the plasma plume; for ceramic powders, the injector is most often located within the plasma gun (i.e., internal injection) to allow direct injection into the plasma plume. As the powder particles are directed into the plume, they are melted and propelled at high velocities onto the surface to be coated, spreading out to form thin "splats" or lamellae structures that comprise the coating [3]. Ideally, one powder particle should result in one lamella; however, some powder particles pass through the plume and are not melted. Lamellae are typically $0.2-0.3 \mu \mathrm{m}$ thick, with each comprised of hundreds of columnar grains which are nominally $200-300 \mathrm{~nm}$ in diameter and oriented parallel with respect to the spray direction. Within the coating, which is essentially made up of numerous lamellae stacked on top of one another, there can be $10-20 \%$ porosity, as well as numerous microcracks and mesocracks, most of which appear to be due to stresses generated during cooling.

One of the disadvantages of the conventional plasma spray process is that powders greater than about $10 \mu \mathrm{m}$ are required to flow properly through a typical powder feeder; powders smaller than these tend to agglomerate due to dominant electrostatic forces unless their surfaces are treated to reduce this attraction. Agglomerated powders clog the supply hose or the injector; moreover, small diameter powders do not typically achieve sufficient momentum transfer from the plasma. It may, however, be desirable to spray powders much smaller than $10 \mu \mathrm{m}$, with the expectation that smaller powders will result in a both smaller lamellae, and possibly smaller grains. The motivation for this work is that early results indicate that nanocrystalline microstructures in coatings improve resistance to thermal cycling [4] in thermal barrier applications.

One approach to create coatings with nanocrystalline features being developed [4-6] is to inject liquids containing ceramic precursors (e.g., aqueous salts) into the plasma. While entrained there, the precursor is converted to crystalline particulates that form via pyrolysis. These newly formed particulates sinter, and ultimately form a nanocrystalline coating. Other researchers $[7,8]$ have started with nanosized powders that were then agglomerated into larger powders via spray drying. These large powder clusters can then be fed into the plasma plume using conventional feeding methods. By careful control of the spray parameters, the nanosized features can be retained.

The current work focuses on another approach to fabricate coatings comprised of nanocrystalline features. The process involves injecting colloidal suspensions of nanocrystalline ceramic powders into the plasma plume. The powders investigated include $40 \mathrm{~nm} \gamma$ $\mathrm{Al}_{2} \mathrm{O}_{3}, 75 \mathrm{~nm} 8 \mathrm{wt} \% \mathrm{Y}_{2} \mathrm{O}_{3}-\mathrm{ZrO}_{2}$, and $750 \mathrm{~nm} 25 \mathrm{wt} \%$ $\mathrm{CeO}_{2}-\mathrm{ZrO}_{2}$. Note that the preceding particle sizes are approximate. During the particles' short residence time in the plasma, the ethanol used to disperse the ceramic powders is vaporized, the powder is melted, and then propelled against the substrate to form the coating. The microstructure of the coating was dependent on the 


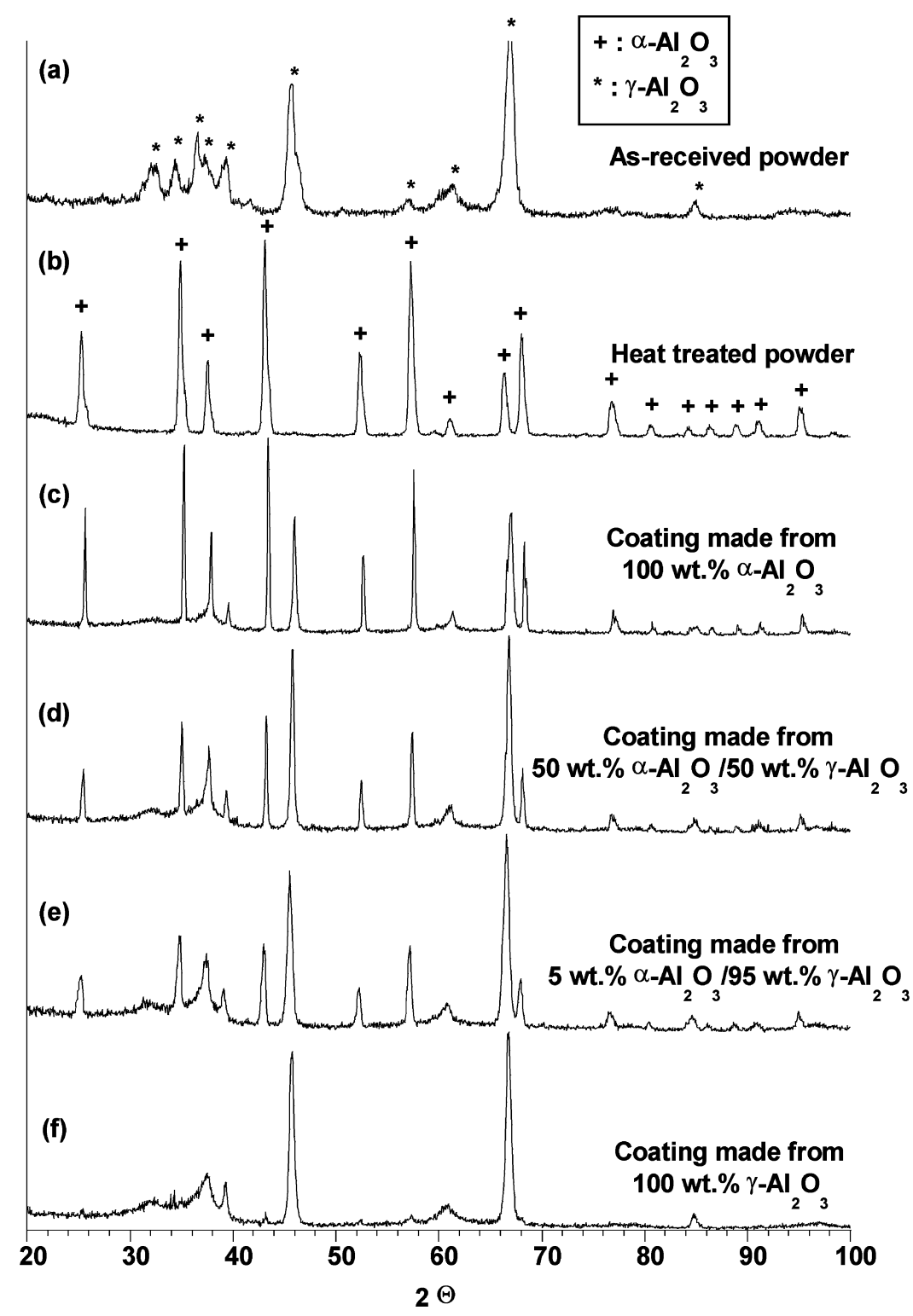

Figure $1 \mathrm{X}$-ray diffraction results for starting powders and coatings made from alumina slurries. The crystal structure and weight based percentage of $\alpha$ - or $\gamma$-alumina starting powder in the slurry is indicated on the plot. The coatings indicated were prepared using a $50 \mathrm{~mm}$ spray distance using the NC conditions indicated in Table II.

starting powder composition. Also, the phase assemblage of the $\mathrm{Al}_{2} \mathrm{O}_{3}$ coatings was strongly influenced by the structure of the starting powders.

\section{Experimental procedure}

\subsection{Description of starting powders}

The $\mathrm{Al}_{2} \mathrm{O}_{3}$ powder ${ }^{1}$ began with a meta-stable $\gamma-\mathrm{Al}_{2} \mathrm{O}_{3}$ crystal structure, a specific surface area of $30-60 \mathrm{~m}^{2} / \mathrm{g}$, and a spherical morphology. Its number-based average diameter was $40 \mathrm{~nm}$ as reported by the manufacturer. The crystal structure was verified via X-ray diffraction (XRD) using a Philips PW 1780 laboratory $\mathrm{Cu} \mathrm{K}_{\alpha}$ diffractometer. The results are shown in Fig. 1a. To investigate the role of starting powder structure on the phases formed in the coating, a portion of the $\gamma-\mathrm{Al}_{2} \mathrm{O}_{3}$ powder was heat treated at $1200^{\circ} \mathrm{C}$ in air for $0.5 \mathrm{~h}$. XRD indicated that the powder completely converted to the stable $\alpha-\mathrm{Al}_{2} \mathrm{O}_{3}$ structure (see Fig. 1b). The as-received and heat-treated $\mathrm{Al}_{2} \mathrm{O}_{3}$ powders were further characterized using a Philips CM30 transmission electron microscope (TEM) operated at $200 \mathrm{kV}$. Fig. 2a and b are bright field and convergent beam electron diffraction (CBED) micrographs, respectively, taken of the starting $\gamma-\mathrm{Al}_{2} \mathrm{O}_{3}$ powder. Note that the powders range in size from 10 to $100 \mathrm{~nm}$. The CBED results presented in Fig. $2 b$ are consistent with the cubic $\gamma-\mathrm{Al}_{2} \mathrm{O}_{3}$ phase. As shown in Fig. 2c, the heat-treated particles sintered to an approximate size of 50 to $300 \mathrm{~nm}$. Also, selected area diffraction analysis of the heat treated powder along the [001] zone axis revealed a hexagonal symmetry, consistent with $\alpha-\mathrm{Al}_{2} \mathrm{O}_{3}$ (see Fig. 2d). During plasma spraying, the flow properties of the heat treated particles were qualitatively the same as the as-received material.

An $8 \mathrm{wt} \%$ yttria-stabilized zirconia powder, ${ }^{2}$ with an number-based average particle size of $75 \mathrm{~nm}$ as determined by a Coulter LS230 particle size analyzer, 


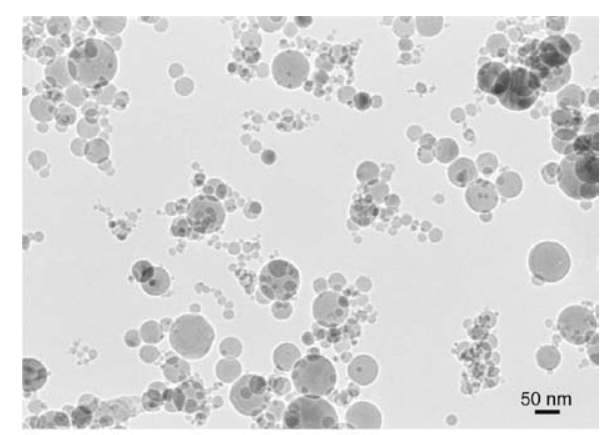

(a)

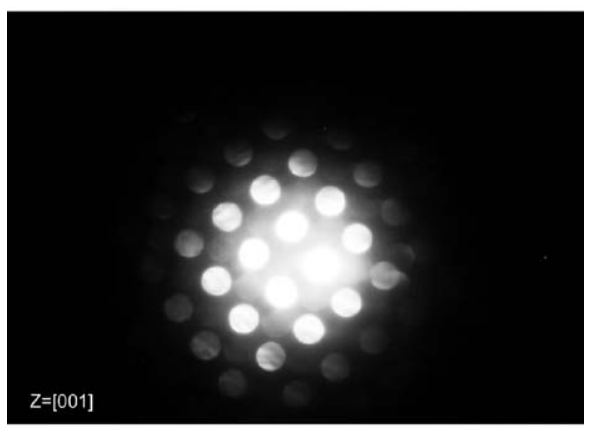

(b)

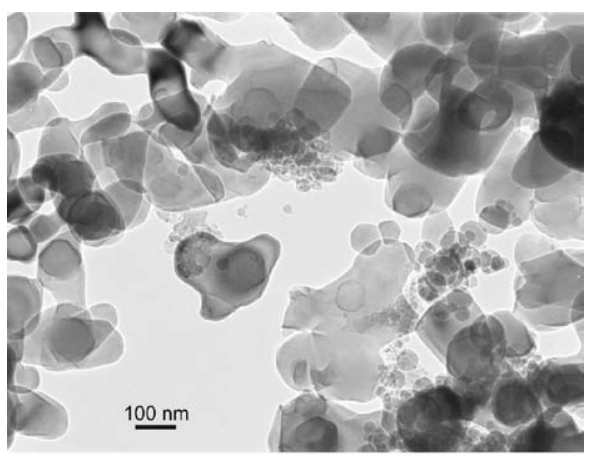

(c)

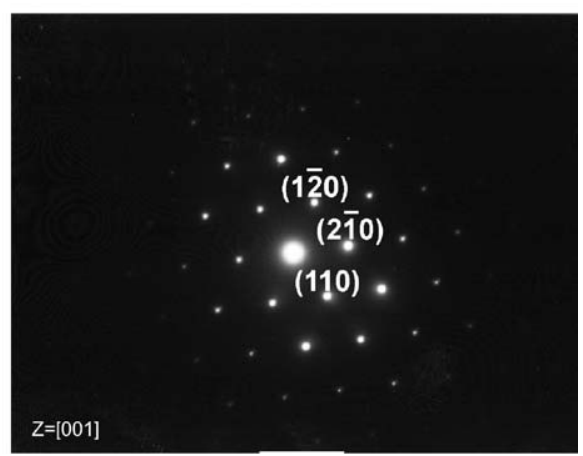

(d)

Figure 2 (a) Bright field TEM image of the as-received $\gamma-\mathrm{Al}_{2} \mathrm{O}_{3}$, (b) CBED pattern for one of the grains indexed along the [001] zone axis consistent with the cubic $\gamma-\mathrm{Al}_{2} \mathrm{O}_{3}$ phase. (c) Bright field TEM image of the heated-treated $\mathrm{Al}_{2} \mathrm{O}_{3}$ powder, (d) and a selected area diffraction pattern from one of the grains indexed along [001] zone axes. The observed symmetry is consistent with the hexagonal structure of $\alpha-\mathrm{Al}_{2} \mathrm{O}_{3}$.

was also investigated. The initial crystal structure of this commercial powder was tetragonal. The $25 \mathrm{wt} \%$ $\mathrm{CeO}_{2}-\mathrm{ZrO}_{2}$ powder was fabricated at Purdue University, starting with zirconia ${ }^{3}$ and ceria powder. ${ }^{4}$ After
TABLE I Comparison of the amount of heat required to completely vaporize water and ethanol in a 100 gram slurry. Ethanol was used in the current study because less heat was required

\begin{tabular}{llll}
\hline Solvent & $\begin{array}{l}\text { Moles of } \\
\text { solvent }^{\mathrm{a}}\end{array}$ & $\begin{array}{l}\text { Total heat required to } \\
\text { vaporize carrier } \\
(\mathrm{kJ} / \mathrm{mole})\end{array}$ & $\begin{array}{l}\text { Total heat } \\
\text { required }(\mathrm{kJ})\end{array}$ \\
\hline $\mathrm{H}_{2} \mathrm{O}$ & 4.2 & 43.98 & 183 \\
$\mathrm{C}_{2} \mathrm{H}_{6} \mathrm{O}$ & 1.63 & 42.32 & 69 \\
\hline
\end{tabular}

a Assuming $75 \mathrm{wt} \%$ solvent and $25 \mathrm{wt} \%$ yttria-stabilized zirconia.

${ }^{\mathrm{b}} \mathrm{H}_{2} \mathrm{O}$ vaporizes at $100^{\circ} \mathrm{C} ; \mathrm{C}_{2} \mathrm{H}_{6} \mathrm{O}$ vaporizes at $78.3^{\circ} \mathrm{C}$.

ball milling these powders for $36 \mathrm{~h}$ using zirconia milling media, the dried powder mixture was sintered at $1350^{\circ} \mathrm{C}$ for $1000 \mathrm{~min}$. X-ray diffraction results revealed that the crystal structure of the ceria-stabilized zirconia powders was predominantly tetragonal, with a small amount $(<5 \mathrm{wt} \%)$ of cubic phase also observed. Using the Coulter LS 230 particle analyzer, the numberbased $d_{50}$ of the sintered powder was measured to be $750 \mathrm{~nm}$.

\subsection{Slurry preparation}

To prepare a coating with sufficient integrity and thickness, it is important that the solvent be completely vaporized, and that there be sufficient remaining heat in the plasma plume to melt the powder. Two solvents were considered: water and ethanol. Table I shows the amount of heat, beginning at $20^{\circ} \mathrm{C}$, required to vaporize either solvent in a 100 gram slurry assuming $75 \mathrm{wt} \%$ solvent and $25 \mathrm{wt} \%$ yttria-stabilized zirconia. The total heat required to vaporize the water and ethanol was 183 and $69 \mathrm{~kJ}$, respectively [9]. Thus, ethanol was the preferred solvent because less heat was required to vaporize it during its brief time in the plume.

A dispersant $t^{5}$ was found to be necessary to prepare a stable, deflocculated slurry. Typically, $1 \mathrm{wt} \%$ of the dispersant was added to the ethanol solvent, and then the YSZ or alumina powder was added. Slurries were mixed such that the solids loading were $25 \%$ by weight. This mixture was ball milled for $10 \mathrm{~h}$ to produce the slurry for plasma spraying. All slurries were agitated during plasma spraying using a magnetic stir rod. In this initial study, no attempt was made to measure residual carbon content after spraying; however, as these coatings were prepared in a highly oxidizing environment, the concentration of carbon would be expect to be minimal.

\subsection{Apparatus for slurry injection into plasma plume}

A $4000 \mathrm{ml}$ stainless steel pressure vessel was used as the holding tank for the slurry. Nitrogen gas at a pressure of $0.3 \mathrm{MPa}$ was used to propel the slurry through the nozzle at a rate of $34 \mathrm{ml} / \mathrm{min}$. Clogging of the nozzle was minimal at this pressure. During injection of the slurry into the plasma plume, the nozzle was tilted back

\footnotetext{
${ }^{3}$ Zirconia Sales, DK-2.

${ }^{4}$ Alfa Aesar, REacton stock \#11328.
}

${ }^{5} \mathrm{KD}-2$ from ICI. 


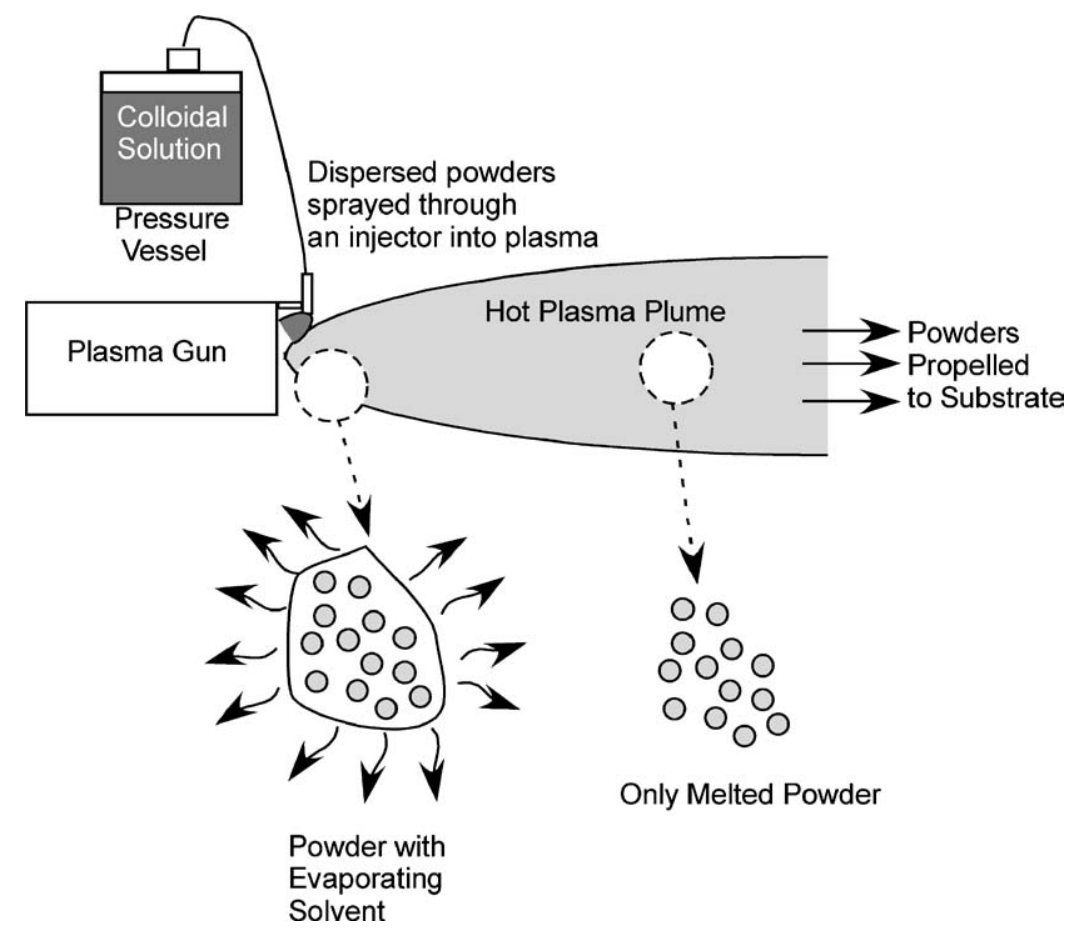

Figure 3 Schematic illustration showing injection of colloidally dispersed powder particles into the plasma-plume.

about $10^{\circ}$ towards the exit of the plasma torch; this arrangement was selected to increase the residence time of the slurry in the plasma plume. The experimental arrangement used in the current study is depicted in Fig. 3.

Air plasma spraying of all slurries was performed at the Ames Laboratory Plasma Spray Facility. For all runs, a Praxair SG-100 gun was assembled with a 145 anode, 129 cathode, and a 113 gas injector, which is commonly used for spraying oxides. Initial coating experiments were performed only using the $\mathrm{Al}_{2} \mathrm{O}_{3}$ powders. The coating conditions used are described as normal $(\mathrm{N})$, normal with cooling $(\mathrm{NC})$, hot $(\mathrm{H})$, and cold (C); conditions $\mathrm{H}$ and $\mathrm{C}$ correspond, respectively, to higher and low plasma energies compared to condition $\mathrm{N}$. The plasma spraying conditions are defined in Table II. A wand having two jets attached to the face of the plasma gun that directed air parallel to the plasma axis onto the substrate was used for cooling in the $\mathrm{NC}$ and $\mathrm{C}$ conditions; moreover, stationary air jets were positioned behind the substrates to increase cooling during deposition. Alumina and zirconia coatings were applied

TABLE II Overview of the four spray conditions employed in the current work. The plasma was created using a mixture of argon and He

\begin{tabular}{|c|c|c|c|c|}
\hline Condition & Normal (N) & $\begin{array}{l}\text { Normal with } \\
\text { cooling (NC) }\end{array}$ & Hot $(\mathrm{H})$ & Cold (C) \\
\hline Current (Amps) & 900 & 900 & 1200 & 600 \\
\hline Voltage (Volts) & 43.6 & 43.6 & 42.2 & 38 \\
\hline $\begin{array}{l}\text { Arc gas, argon } \\
\quad(\text { slpm })\end{array}$ & 70.5 & 70.5 & 42.0 & 150 \\
\hline $\begin{array}{l}\text { Auxilliary gas, } \\
\text { He (slpm) }\end{array}$ & 42.0 & 42.0 & 42.0 & 0 \\
\hline $\begin{array}{l}\text { Slurry pressure } \\
\qquad(\mathrm{MPa})\end{array}$ & 0.3 & 0.3 & 0.3 & 0.3 \\
\hline Cooling & None & Wand and jets & None & Wand and jets \\
\hline
\end{tabular}

to stainless steel and copper substrates, respectively, at $50,63,75$, and $100 \mathrm{~mm}$ distances from the plasma gun exit. Sprayed surfaces were grit blasted with 24 grit $\mathrm{Al}_{2} \mathrm{O}_{3}$ followed by ultrasonic cleaning in ethanol. The $x-y$ manipulator used to control the plasma gun was passed horizontally across the substrate at $100 \mathrm{~mm} / \mathrm{s}$, and then moved vertically in $3 \mathrm{~mm}$ steps to cover the entire $[18 \times 30 \times 2 \mathrm{~mm}]$ substrate. This sequence was repeated 20 times to comprise a complete coating program. However, the program was stopped if the nozzle became clogged or if the slurry was consumed prior to the 20 th cycle.

\subsection{Specimen preparation and characterization}

Coatings were analyzed by XRD similarly to the starting powders. In particular, XRD was used to examine the correlation in phase structure between starting powders and final coatings using powders having various ratios by weight of $\alpha-\mathrm{Al}_{2} \mathrm{O}_{3}$ and $\gamma-\mathrm{Al}_{2} \mathrm{O}_{3}$, and to determine the phase(s) present in the plasma-sprayed zirconia coatings.

TEM specimens of coatings were prepared by first removing the coating from the substrate. Alumina coatings were removed from the steel substrates by deforming the metal substrate; coatings were removed from the copper substrates by etching in hydrochloric acid. Cross-section and plan-view (TEM) specimens were prepared using a tripod polisher. ${ }^{6}$ Each specimen was polished progressively using a sequence of 30,6 , and $1 \mu \mathrm{m}$ diamond coated polishing films for both sides. After transferring the thinned coating to a copper grid, further thinning of the sprayed coatings was performed

\footnotetext{
${ }^{6}$ South Bay Technology, Santa Clara, CA.
} 
using a low-energy ion mill ${ }^{7}$ equipped with two hollow anode discharge ion sources that were both set to $4.5 \mathrm{kV}$ and $0.5 \mathrm{~mA}$. The TEM observations on coatings were performed with a Jeol JEM-2000 FX instrument at an accelerating voltage of $200 \mathrm{kV}$.

Two different coatings prepared with the $8 \mathrm{wt} \%$ $\mathrm{Y}_{2} \mathrm{O}_{3}-\mathrm{ZrO}_{2}$ powder were analyzed using atomic force microscopy (AFM): one coating made from $75 \mathrm{~nm}$ powder, the other from $50 \mu \mathrm{m}$ powder. Specimens oriented to examine their cross section were prepared by polishing both sides of the coating first with 600 grit $\mathrm{SiC}$ polishing paper, and then with diamond-coated polishing films down to $1 \mu \mathrm{m}$. The samples were subsequently thermally etched at $1200^{\circ} \mathrm{C}$ for $2 \mathrm{~h}$ to reveal boundaries between lamellae and grains. AFM images were obtained using a Digital Instrument Multimode Scanning Probe Microscope ${ }^{8}$ in tapping mode.

\section{Results and discussion}

\subsection{Role of spraying distance and spraying conditions}

For all powders investigated, deposition was most efficient at a $50 \mathrm{~mm}$ spray distance, i.e., at this spray distance the thickest coatings were achieved. With each pass of the plasma gun, approximately $12 \mu \mathrm{m}$ of coating were applied. Measurable, but lower, deposition rates were obtained at $63 \mathrm{~mm}$. Because of the short spray distances required for significant deposition of the nanosized powders, coatings made at distances of 50 to $63 \mathrm{~mm}$ would spall off the substrate unless cooling air was directed to the substrate via the jets described in the experimental procedure (i.e., conditions $\mathrm{NC}$ and $\mathrm{C}$ ). The reason for spallation of the coating was likely poor adhesion of the partially melted powders with the substrate. No measurable coating thickness was obtained in coatings formed using spray distances of 75 and $100 \mathrm{~mm}$.

The NC spray conditions produced the highest quality coatings, as determined by deposition rate and coating integrity (e.g., density as observed by metallography) for all powders investigated. No coatings were successfully formed using the $\mathrm{N}$ and $\mathrm{H}$ spray conditions (as described in Table II) due to overheating of the substrate and spallation of the coating. The substrate temperature was observed to exceed $400^{\circ} \mathrm{C}$ at all spray distances for the $\mathrm{N}$ and $\mathrm{H}$ spray conditions. The $\mathrm{C}$ spray condition yielded very low deposition efficiencies, presumably due to decreased solvent vaporization, particle melting or low particle velocity.

\subsection{Coatings obtained from alumina slurries}

As is well established, $\gamma-\mathrm{Al}_{2} \mathrm{O}_{3}$ is one of the intermediate phases formed when alumina is plasma sprayed [10]. Upon cooling from the melting temperature of alumina $\left(2060^{\circ} \mathrm{C}\right), \gamma-\mathrm{Al}_{2} \mathrm{O}_{3}$ nucleates first over $\alpha-\mathrm{Al}_{2} \mathrm{O}_{3}$, and thus, plasma-sprayed coatings typically are com-

\footnotetext{
${ }^{7}$ Gatan $^{\circledR}$, model DMP 600.

${ }^{8}$ Digital Instruments, Santa Barbara, CA.
}

posed almost entirely of $\gamma-\mathrm{Al}_{2} \mathrm{O}_{3}$. Therefore, $\gamma-\mathrm{Al}_{2} \mathrm{O}_{3}$ is a marker that can be used to indicate whether the starting $\alpha-\mathrm{Al}_{2} \mathrm{O}_{3}$ melted in the plume. Fig. $1 \mathrm{c}-\mathrm{f}$ displays the XRD results of coatings produced from slurries with different amounts of starting $\alpha$ - and $\gamma-\mathrm{Al}_{2} \mathrm{O}_{3}$ powders. These coatings were all sprayed at a distance of $50 \mathrm{~mm}$ from the substrate using the $\mathrm{NC}$ condition. Since the coating fabricated from the slurry composed of $100 \mathrm{wt} \% \alpha-\mathrm{Al}_{2} \mathrm{O}_{3}$ has only a small fraction of $\gamma-$ $\mathrm{Al}_{2} \mathrm{O}_{3}$ (see Fig. 1c), the XRD data indicate that only a small amount of powder was melted during spraying.

As shown in Fig. 1d, the coating formed from the $50 \mathrm{wt} \% \alpha-\mathrm{Al}_{2} \mathrm{O}_{3} / 50 \mathrm{wt} \% \quad \gamma-\mathrm{Al}_{2} \mathrm{O}_{3}$ slurry was comprised of approximately equal amounts of each phase. These estimations were based on comparing integrated $\mathrm{X}$-ray intensities from several powder mixtures having known rations of $\alpha-\mathrm{Al}_{2} \mathrm{O}_{3}$ and $\gamma-\mathrm{Al}_{2} \mathrm{O}_{3}$. Similarly, coatings formed from a slurry composed of $5 \mathrm{wt} \%$ $\alpha-\mathrm{Al}_{2} \mathrm{O}_{3} / 95 \mathrm{wt} \% \quad \gamma-\mathrm{Al}_{2} \mathrm{O}_{3}$ retained a similar ratio of these two phases (Fig. 1e). The coating made from the slurry with $100 \% \gamma-\mathrm{Al}_{2} \mathrm{O}_{3}$ was mainly composed of the $\gamma-\mathrm{Al}_{2} \mathrm{O}_{3}$ phase (Fig. 1f). Together, the preceding results strongly suggest that the $\mathrm{NC}$ plasma spraying

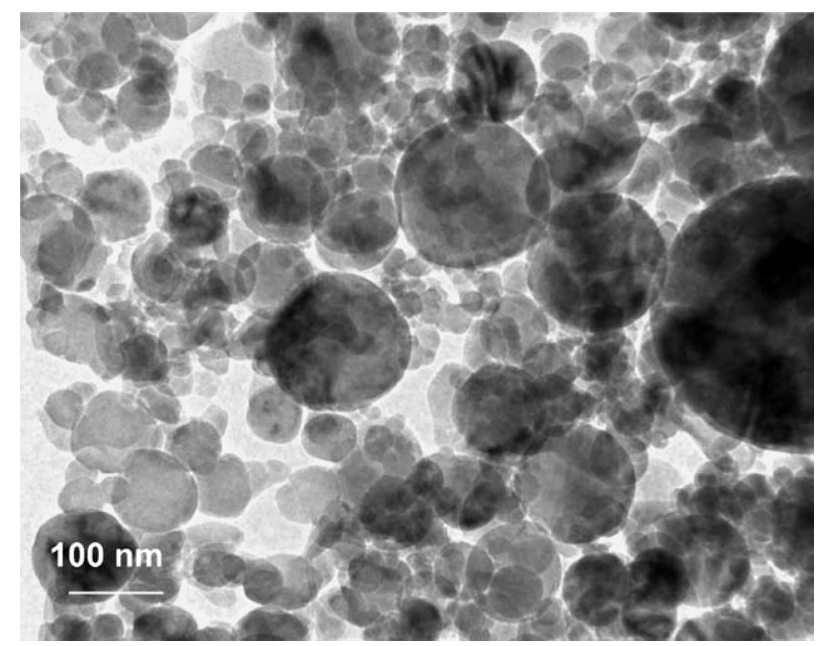

(a)

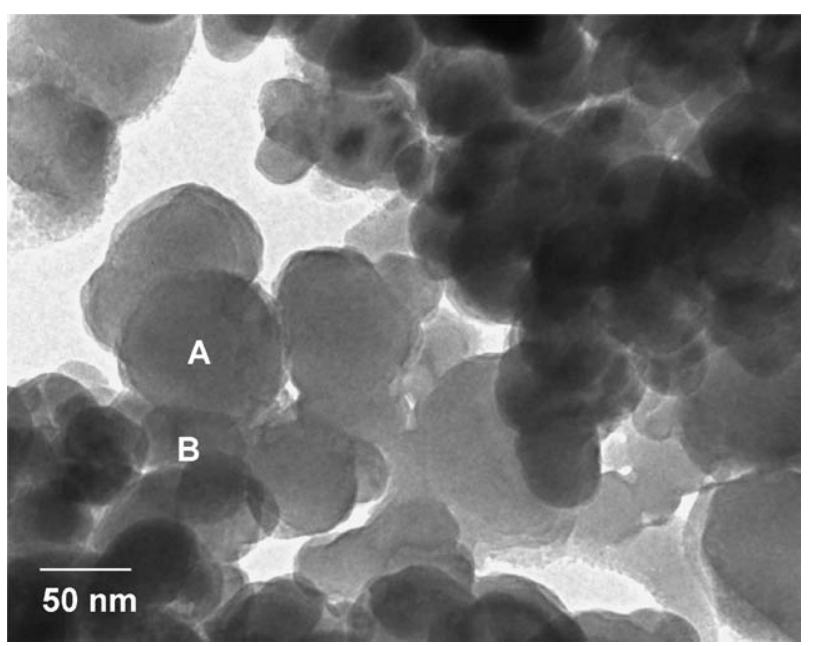

(b)

Figure 4 Bright field TEM micrograph of a coating prepared by spraying an alumina slurry composed of $50 \mathrm{wt} \% \gamma-\mathrm{Al}_{2} \mathrm{O}_{3} / 50 \mathrm{wt} \% \alpha-\mathrm{Al}_{2} \mathrm{O}_{3}$ in the plan-view orientation showing: (a) individual powder particles and (b) evidence of sintering between the powder particles labeled A and B. 
conditions, inclusive of the slurry delivery and injection techniques, do not lead to significant melting of the nano-sized alumina powders. As described below, microstructural analysis of the alumina coatings indicates the occurrence of some sintering of powder particles within the plasma plume or after striking the substrate, perhaps in the presence of the plasma as a consequence of the short spraying distance (i.e., $50 \mathrm{~mm}$ ).

Fig. 4a displays a bright field TEM micrograph of a coating made with a slurry containing $50 \mathrm{wt} \% \alpha$ $\mathrm{Al}_{2} \mathrm{O}_{3} / 50 \mathrm{wt} \% \gamma-\mathrm{Al}_{2} \mathrm{O}_{3}$. Individual powder particles having sizes ranging from $20 \mathrm{~nm}$ through $200 \mathrm{~nm}$ can be clearly distinguished in the micrograph. The spherical morphology of the powders was similar to that observed in the starting $\gamma-\mathrm{Al}_{2} \mathrm{O}_{3}$ powder. Thus, it appears that in principle the approach taken to feed the powders into the plume was effective (i.e., the nanosized dimensions are retained). Fig. $4 \mathrm{a}$ also reveals that the characteristic lamellar structure normally apparent in plasma-sprayed coatings is not present in the alumina coatings. From the results of the XRD data, it is clear that the reason for this is that most of the powder was not melted, and therefore maintains its spherical shape upon impact with the substrate. Inspection of the coating surface indicated that the coating was fairly abrasion resistant, as determined simply by scratching with a metal file. Thus, the coating demonstrated some strength, implying that the powders were more than loosely agglomerated onto the substrate surface. The coating morphology observed in
Fig. $4 \mathrm{~b}$ is consistent with this observation, showing two adjacent powder particles that have joined together during the spray process or during subsequent passes of the torch over the coating/substrate.

\subsection{Zirconia slurries}

Based on the prior results with spraying the alumina slurries, all zirconia powders were sprayed under the $\mathrm{NC}$ condition. Fig. 5a and $\mathrm{b}$ are the XRD results for the $8 \mathrm{wt} \% \quad \mathrm{Y}_{2} \mathrm{O}_{3}-\mathrm{ZrO}_{2}$ starting zirconia powders and the final coatings produced from the sprayed slurries. The starting $8 \mathrm{wt} \% \mathrm{Y}_{2} \mathrm{O}_{3}-\mathrm{ZrO}_{2}$ powder and the resulting coating have similar tetragonal structures. Analysis of diffraction peaks between $72-76^{\circ}$ indicated that an yttrium-rich tetragonal phase was formed [11]. This yttrium-rich tetragonal phase is typically observed when large-diameter yttria-stabilized zirconia powders are plasma sprayed. Similarly, no change between final coating phase composition and the starting powder was observed for the $25 \mathrm{wt} \% \mathrm{CeO}_{2}-\mathrm{ZrO}_{2}$ powder (see Fig. $5 \mathrm{c}$ and d). The $25 \mathrm{wt} \% \mathrm{CeO}_{2}-\mathrm{ZrO}_{2}$ powder coating exhibits slightly more peak broadening than the starting powders, which may indicate the these larger particles experienced some degree of melting that led to a reduced grain size during quenching upon impact with the substrate. Further evidence of particle melting during spraying of the zirconia powders was observed during TEM analysis, as discussed below.

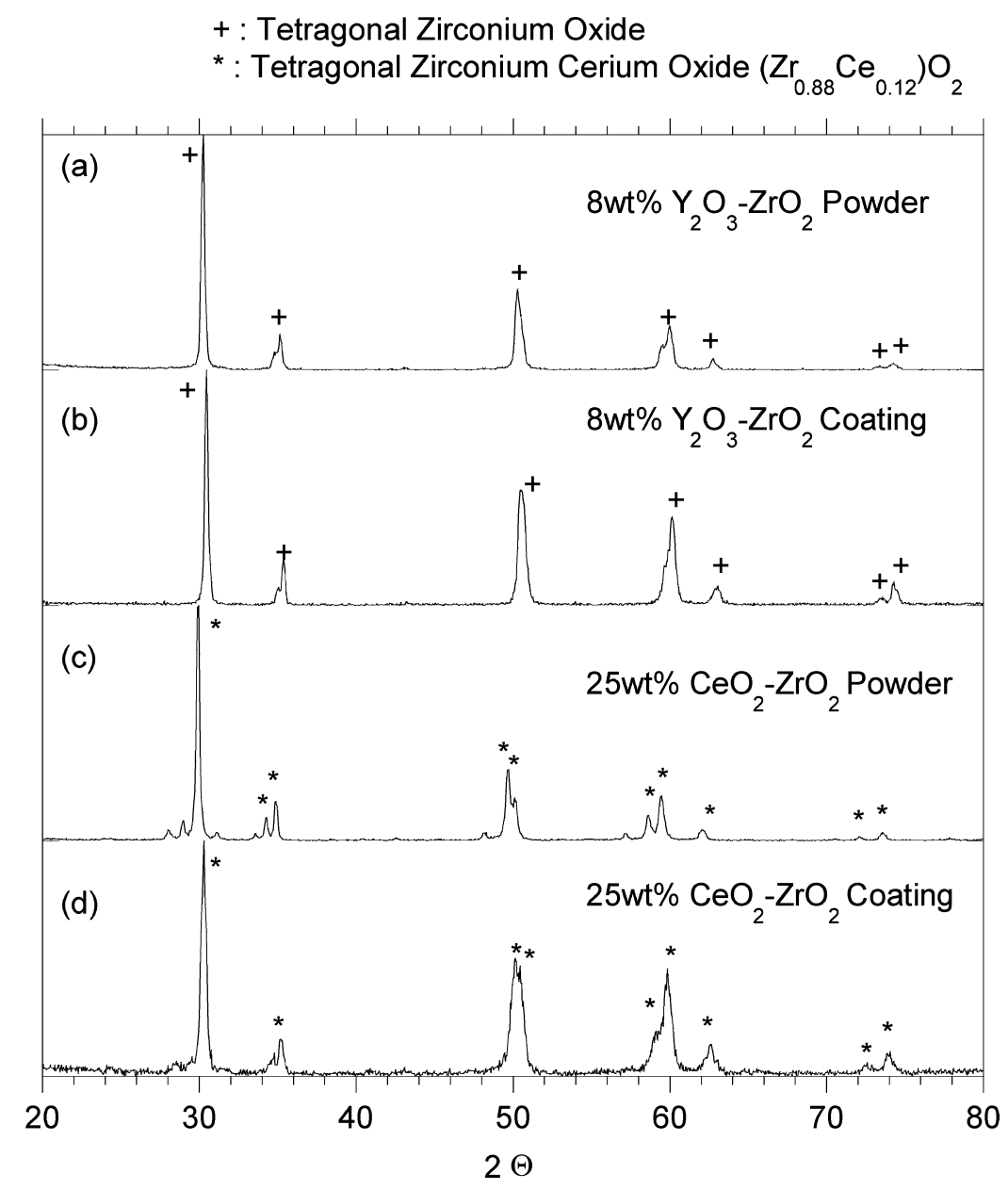

Figure 5 X-ray diffraction results for coatings made from the $8 \mathrm{wt} \% \mathrm{Y}_{2} \mathrm{O}_{3}-\mathrm{ZrO}_{2}$ and $25 \mathrm{wt} \% \mathrm{CeO}_{2}-\mathrm{ZrO}_{2}$ slurries. For each composition, the phases observed in the starting powder and coating were the same. 


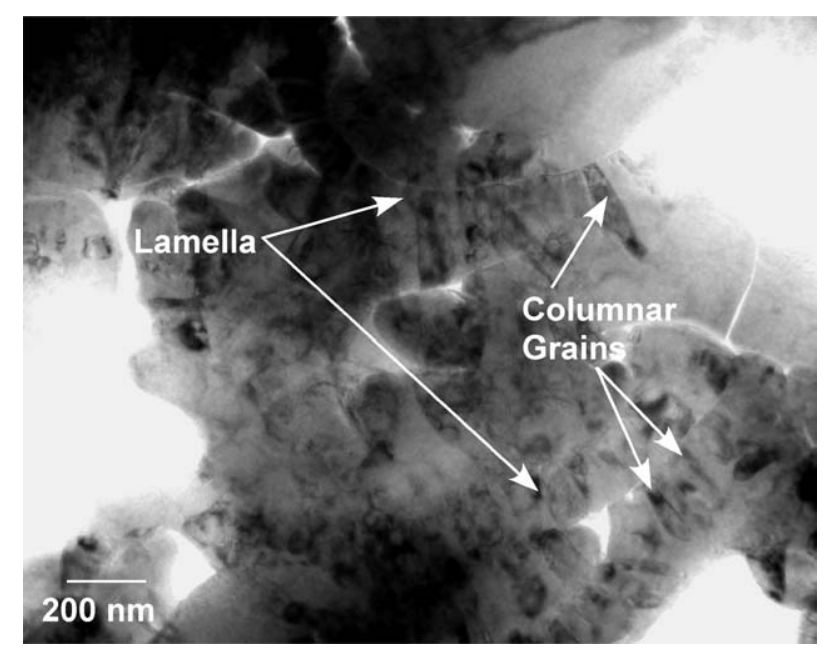

Figure 6 Bright field TEM micrograph of the plasma-sprayed $8 \mathrm{wt} \%$ $\mathrm{Y}_{2} \mathrm{O}_{3}-\mathrm{ZrO}_{2}$ slurry in the plan-view orientation. Note the thin lamella formed during spraying.

Fig. 6 displays a bright field TEM micrograph of a coating made from nano-crystalline $8 \mathrm{wt} \% \mathrm{Y}_{2} \mathrm{O}_{3}-\mathrm{ZrO}_{2}$ powder. This image reveals that the powder particles melted while in the plasma because lamellae or splats are clearly visible; the thin lamellae do not form unless the powders are melted and possess enough kinetic energy to overcome surface tension (and flatten) upon contact with the substrate [12]. In this particular planview oriented TEM micrograph, several thin lamellae can be seen. They are typically 100-200 nm thick, and consist of columnar grains with approximate diameters of $20-40 \mathrm{~nm}$. As the starting powder was nominally $75 \mathrm{~nm}$ in diameter, it appears that some agglomeration of the powder particles occurred during plasma spraying. However, the features of the coating are still quite small compared to conventional coatings produced with particles generally $>20 \mu \mathrm{m}$. Although not shown in Fig. 6, unmelted, or perhaps melted and re-solidified particles were observed. Similarly shaped particles are well known to be occasionally present to some degree in conventional zirconia coatings. Fig. 7 is a typical crosssection bright field TEM image from the $25 \mathrm{wt} \mathrm{CeO}_{2}-$ $\mathrm{ZrO}_{2}$ coating. Many individual lamellae are present and

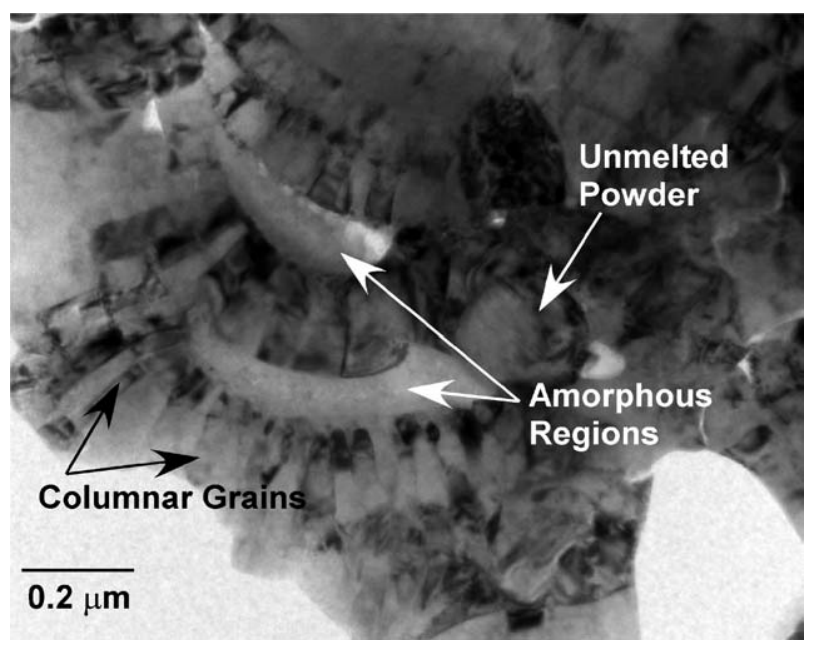

Figure 7 A cross-sectional bright field TEM image of a $25 \mathrm{wt} \% \mathrm{CeO}_{2}-$ $\mathrm{ZrO}_{2}$ coating with individual lamellae and columnar grains, and an unmelted particle all apparent.

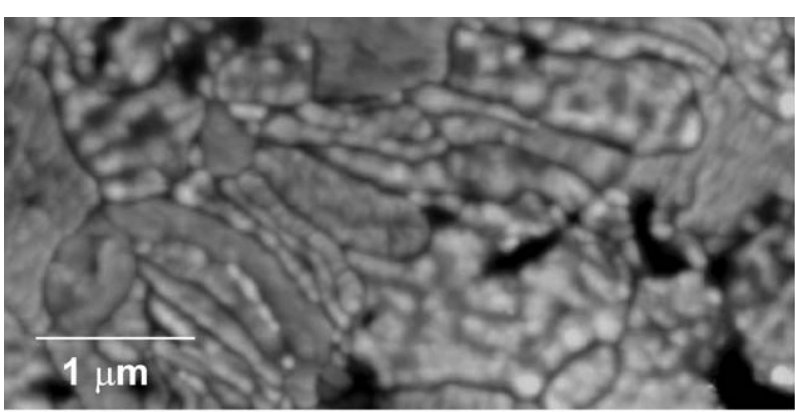

(a)

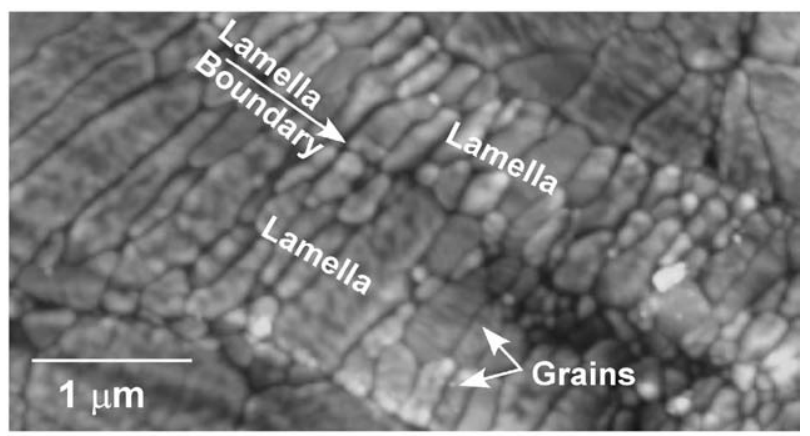

(b)

Figure 8 Atomic force microscopy results of $8 \mathrm{wt} \% \mathrm{Y}_{2} \mathrm{O}_{3}-\mathrm{ZrO}_{2}$ plasmasprayed coatings made using (a) colloidal solutions of nanosized $8 \mathrm{wt} \%$ $\mathrm{Y}_{2} \mathrm{O}_{3}-\mathrm{ZrO}_{2}$ and (b) conventionally sprayed (i.e. powder fed) $50 \mu \mathrm{m}$ diameter $8 \mathrm{wt} \% \mathrm{Y}_{2} \mathrm{O}_{3}-\mathrm{ZrO}_{2}$. Both micrographs are in the cross-sectional orientation.

are built up of grains that are nominally $40-60 \mathrm{~nm}$ in diameter. A single large unmelted powder particle was observed, as indicated on the micrograph. Some amorphous regions between the lamella were observed.

\subsection{Comparison to conventionally sprayed coatings}

Atomic force microscopy was used to compare the cross-sectional microstructure of $8 \mathrm{wt} \% \mathrm{Y}_{2} \mathrm{O}_{3}-\mathrm{ZrO}_{2}$ plasma sprayed coatings prepared in this study to conventionally fed and plasma sprayed $50 \mu \mathrm{m}$ diameter $8 \mathrm{wt} \% \mathrm{Y}_{2} \mathrm{O}_{3}-\mathrm{ZrO}_{2}$ powders. Prior to testing, each coating was polished to $1 \mu \mathrm{m}$ and then thermally etched at $1200^{\circ} \mathrm{C}$ for 0.5 h. The results are shown in Fig. 8 . The coating made with the nano-sized zirconia, Fig. 8a, shows multiple lamellae of similar scale to those observed in Fig. 6. In some regions, it is possible to resolve the individual columnar grains. A cross-sectional view of the $50 \mu \mathrm{m}$ diameter zirconia powders is displayed in Fig. 8b. Only two large lamellae are present, indicating that the lamellae were made from larger powders. Clearly the microstructural features of the coating fabricated from the nanosized powders are finer.

\section{Conclusions}

Plasma sprayed coatings made from nanosized powders were fabricated and characterized. The powders investigated included $40 \mathrm{~nm} \gamma-\mathrm{Al}_{2} \mathrm{O}_{3}, 75 \mathrm{~nm} 8 \mathrm{wt} \%$ 
$\mathrm{Y}_{2} \mathrm{O}_{3}-\mathrm{ZrO}_{2}$, and $750 \mathrm{~nm} 25 \mathrm{wt} \% \mathrm{CeO}_{2}-\mathrm{ZrO}_{2}$. Because of the difficulty feeding small powders into a plasma plume, ethanol-based colloidal slurries of each powder were prepared and fed into the plasma using a fine-spray injector under pressurized nitrogen. Coating deposition rates were higher for small spray distances $(50 \mathrm{~mm})$ and spray conditions that included cooling for the substrate. Coatings made from the $40 \mathrm{~nm} \gamma-\mathrm{Al}_{2} \mathrm{O}_{3}$ did not completely melt during spraying, as determined by XRD and TEM investigations. Thus, the microstructure of the coating was comprised of small spherical powders that were partially sintered. TEM observation of coatings made from zirconia powders (both compositions) revealed thin lamellae (100-200 nm thick), evidence that the powders had completely or at least partially melted while in the plasma plume. The grains that made up individual lamellae were much smaller, ranging from 10 $40 \mathrm{~nm}$ in diameter. Lamellae size seemed to scale with the starting powder size. Some evidence of agglomeration of melted powders in the plume was observed for the zirconia powders.

\section{Acknowledgements}

The work at Ames Laboratory was supported by the United States Department of Energy (USDOE), Office of Science (OS), Office of Basic Energy Sciences (BES), through Iowa State University under Contract W-7405-ENG-82. Efforts performed at Purdue
University were supported by a grant from the California Energy Commission under Contract 51979A/00-22.

\section{References}

1. R. B. HEIMAN N, "Plasma-Spray Coating: Principles and Applications" (VCH, 1996).

2. L. PAWLOWSKI, "The Science and Engineering of Thermal Spray Coatings" (Wiley, 1995).

3. R. McPHER S ON, Surf. Coat. Tech. 39/40 (1989) 173.

4. N. P. PADTURE, K. W. SCHLiChting,. T. Bhatia, A. OZTURK, B. CETEGEN, E. H. JORDAN, M. GELL, S. JIANG, T D. XIAO, P. R. STRUTT, E. GARCIA, P. MIRANZO and M. I. OSENDI, Acta Mater. 49(12) (2001) 2251.

5. T. BHATIA, A. OZTURK, L. XIE, E. JORDAN, B. CETEGen, M. GELl, X. MA and N. PADTURE, J. Mater. Res. 17(9) (2002) 2363.

6. G.-M. CHOW, L. K. KURIHARA, T. D. XIAO, P. R. STRUTT, C. W. STROCK and R. A. ZATORSKI, U. S. Patent no. 6,447,848 (2002).

7. L. L. SHAW, D. GOBERMAN, R. REN, M. GELL, S . JIANG, Y. WANG, T. D. XIAO and P. R. STRUTT, Surf. Coat. Tech. 130 (2000) 1.

8. H. CHEN and C. X. DING, ibid. 150 (2002) 31.

9. "CRC Handbook of Chemistry and Physics", 82nd ed., editor-inchief, David R. Lide (CRC Press, Boca Raton, FL, 2001-2002) pp. 5-18, 5-31, 6-109, 6-110.

10. R. MCPHERSON, J. Mater. Sci. Let. 15 (1980) 3141.

11. K. MURALEEDHARAN, J. SUBRAHMANYAM and S. B. B HA DUR I, J. Amer. Ceram. Soc. 71(5) (1988) C226.

12. R. McPHERS ON, Thin Solid Films 83 (1981) 297.

Received 31 July 2003

and accepted 9 March 2004 